\title{
CAFÉ, INCERTIDUMBRE Y REDES CADA VEZ MÁS FUERTES
}
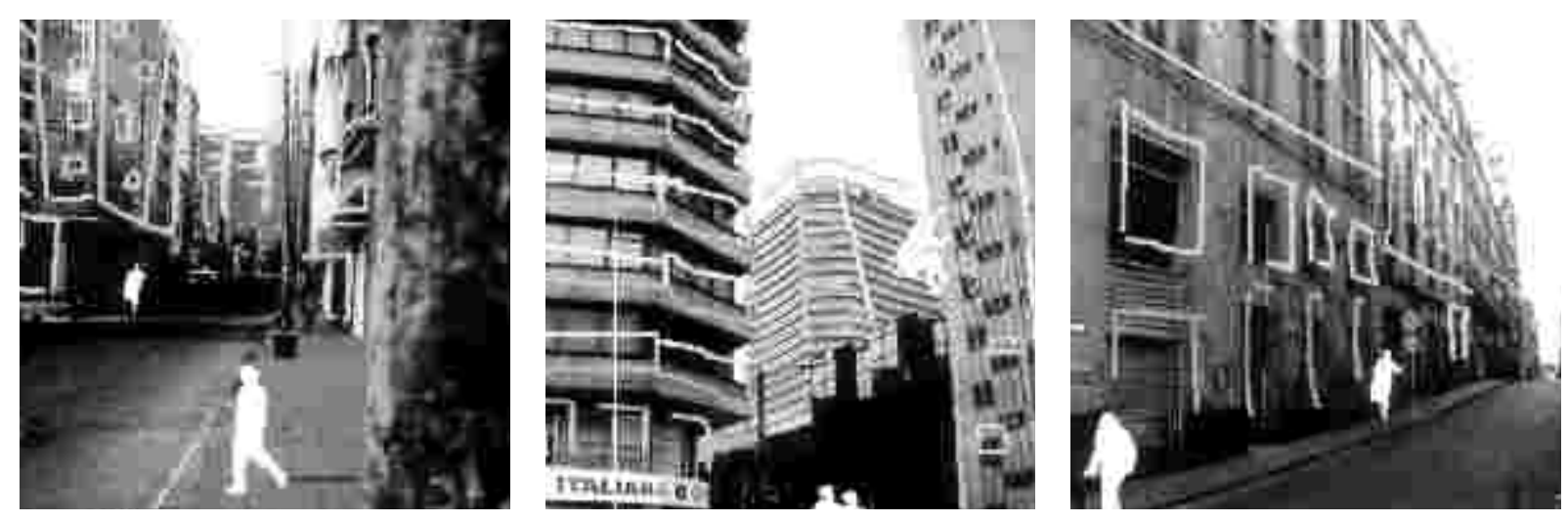

"Ciudadanías de la Incertidumbre. Comunicación, poder y subjetividad" fue el nombre del XII Encuentro Latinoamericano de la Federación Latinoamericana de Facultades de Comunicación Social (Felafacs). Este evento académico se unió a la conmemoración de los 25 años de Felafacs - que reúne más de 300 facultades y/o escuelas de comunicación de 21 países latinoamericanos. $Y$ como no hay dos sin tres, también coincidió con el festejo de los 70 años del inicio de los cursos de periodismo en la universidad sede, la Pontificia Universidad J averiana de Bogotá, Colombia. El clima de festejo, sin embargo, no opacó la finalidad del encuentro, sino que fortaleció las relaciones de los participantes, que entre conferencistas, ponentes, docentes y estudiantes, Il egaron a los 1.500 inscriptos.

"El miedo y el pánico son los grandes argumentos de la política moderna [...] asistimos a un relanzamiento del pánico y tenemos que trabajar mucho para comprenderlo y combatirlo..."

Paul Virilio, Ciudad Pánico, 2006.
Cuatro días de intensos intercambios académicos e investigativos, que parecieron no ser suficientes para ¿qué papel cumplen los medios masivos de comunicación en la producción, circulación de la seguridad y el miedo? ¿cuál es el consumo simbólico de éste? ¿cuáles son los discursos del miedo en la producción de ciudadanías de la incertidumbre?

El primer conferencista, Jesús Martín Barbero, dio la "bienvenida" a esa incertidumbre "si nos saca de las certezas falsas, trucadas, de los dogmatismos, si nos dialogar sobre las grandes preguntas del encuentro: vacuna contra el pensamiento único". En su exposición, Martín Barbero celebró que Felafacs hubiera elegido el tema de la incertidumbre y los miedos. De hecho, recalcó la importancia que tuvo dicha decisión al presentar la comunicación no desde una óptica leve, artificial, del "mito que todo lo cohesiona" o del "show tecnológico", sino exponiendo el verdadero ojo de la tormenta. Pensar la comunicación también como "una pesadilla que desuney rompe. [...] Podemos pensar que los medios construyen lo real. o como J ean Baudrillard, pensar que los medios destruyen lo real construyendo simulacros tramposos de lo real. De alguna manera, ambas visiones tienen algo de verdad. Pero las medias verdades, decía mi abuela, son las peores mentiras. ¿Por qué cuando creíamos que sabíamos lo que pasaba vino el 11 de setiembre y nos sorprendió?; la destruc-ción de las torres gemelas tuvo la capacidad de mostrarnos que los medios de comunicación ni son capaces de mediatizar completamente la realidad, ni mucho menos son capaces de suplantarla".

Estas discusiones se dan en un contexto de ciudadanías de la incertidumbre. Es decir, de ciudadanías - término que se ha convertido en campo de debate en las ciencias sociales- que implican un deber ser en la igualdad de la integración social en un Estado moderno. Sin embargo, es verdad que el estatus de 
ciudadano no implica siempre lamen-tablemente, la condición de justicia. Y muchos menos en un momento de incertidumbre, de una época de pérdidas de confianza en las utopías, donde el control (característica de la modernidad) ha dado lugar al descontrol (eje de la "sobremodernidad"), en una sociedad en la que cada vez más surgen causas de nuevos "miedos".

Para tratar de entender la realidad en que se vive y la relación de los medios masivos de comunicación, el encuentro se desarrolló en varias actividades. Las conferencias magistrales estuvieron a cargo de la cientista política Chantal Mouffe, que actualmente enseña en la University of W estminster de Inglaterra; Nelly Richard, directora y fundadora de la Revista de Crítica Cultural; y Rosana Reguillo, profesora de Estudios Socioculturales del Instituto Tecnológico de Estudios Superiores de Occidente (ITESO) y titular de la Cátedra UNESCO de Comunicación de la Universidad Autónoma de Barcelona. También se realizaron paneles con diversos investigadores latinoamericanos como Alejandro Grimson, Carlos Scolari, Pilar Riaño, Rosa María Alfaro, Benjamín Arditi, Javier Corral, Eliseo Colón y la española Carmen Caffarel. La sorpresa fue la presencia de Antanas Mockus, ex-rector de la Universidad Nacional de Colombia, ex-alcalde de Bogotá y expresidenciable, quien expuso la exitosa estrategia de comunicación contra la violencia y el consumo abusivo de alcohol que desarrolló durante sus dos períodos en la ciudad.

A su vez, para un mayor intercambio con los futuros comunicadores, se generaron espacios llamados conversatorios estudiantiles, en que los ponentes anteriores recibieron preguntas directas de los alumnos. Dieciséis mesas de trabajo reunieron a un centenar de investigadores que durante tres días discutieron, polemizaron y tejieron redes. Durante esos días, se aprovechó la oportunidad de presentar varios libros alusivos al tema, como Entre miedos y goces. Comunicación, vida pública y ciudadanías de los autores académicos José Miguel Pereira y Mirla Villadiego Prins (Editorial Pontificia Universidad Javeriana, Bogotá, 2006) y Narrativas Mediáticas. 0 cómo se cuenta a la sociedad del entretenimiento del colombiano Omar Rincón (Gedisa, Barcelona, 2006).

Un actor a destacar en este encuentro fue el estudiante. Tanto el de la J averiana, que puso toda su energía en la organización del mismo, como los que fueron a participar. El movimiento fue constante en el ir y venir de una conferencia a un panel, así como en la participación en los diversos concursos que Felafacs propone a los futuros comunicadores. Uruguay tuvo su premio en el III Festival Iberoamericano de Creación Audiovisual Universitaria, en el género documental, con "Gato de porcelana", de los egresados de la Licenciatura en Comunicación Social de la Universidad Católica, Natalia Espasandín, Mariangel Perdomo, Marianna Germano y Pablo Casaretto.

El encuentro cerró con una nota fuerte cuando los estudiantes venezolanos pidieron el micrófono para leer una "proclama" en el cierre de la ceremonia final. Hicieron manifiesto y explícito el poco debate sobre los medios masivos y la relación con su presidente Hugo Chávez. En un discurso muy aséptico, evidenciaron el vacío de los propios investigadores y ponentes de Venezuela en dar una opinión sobre esa situación. Es decir, cuando ellos participaban de las mesas, de alguna forma u otra se trataba de evadir el asunto. Los estudiantes reclamaron que se "teorizara" sobre esto; quisieron hablar de los temas importantes, y como dijo Martín-Barbero, no dejar a las cosas en el estatuto de "las medias verdades", en esa incertidumbreque paraliza y no construye. 